\title{
Educação a partir da sapiência dos oprimidos
}

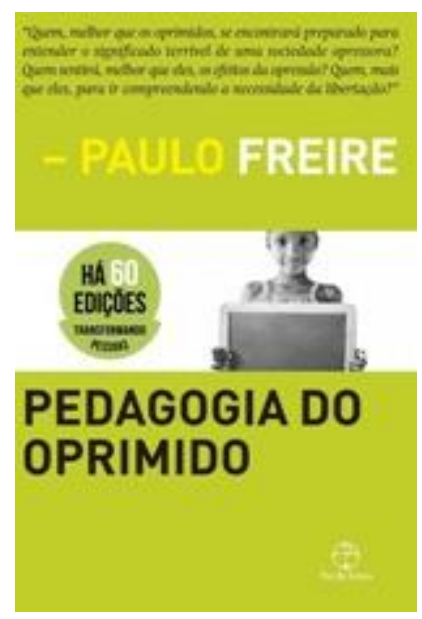

FREIRE, Paulo. Pedagogia do oprimido. 60 ed. Rio de Janeiro: Paz e Terra, 2016. 288 p. ISBN 978-85-775-3336-7.

\section{Daniel Ribeiro de Almeida Chacon}

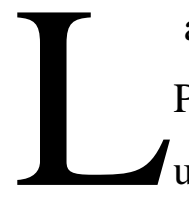
aureado com a designação de patrono da educação brasileira, Paulo Freire foi, seguramente, um icônico humanista cristão e um notável intelectual do século XX. A obra Pedagogia do oprimido desvela, de modo singular, a politicidade da educação. Em que se pese a natureza conceitual do problema, esse escrito se faz irredutível a qualquer forma de especulação impassível e estéril. A proposta pedagógica de Freire consiste numa educação dialógica, participante, problematizadora e emancipatória, na qual o oprimido possa libertar-se a si mesmo das amarras da coisificação, para, assim, exercer sua própria vocação ontológica de "ser-mais", de ser sujeito cognoscente, autor de sua própria história através da práxis. Com efeito, o projeto freiriano de uma pedagogia contextualizada, i.e., forjada a partir do oprimido, de sua própria linguagem e valores, se funda, necessariamente, na fé nas pessoas. Dito de outro modo, a confiança no povo é uma condição imprescindível para a própria revolução.

Considerado, pois, como seu mais célebre escrito, Pedagogia do oprimido se constitui em quatro capítulos, precedidos, porém, de uma breve,

${ }^{1}$ Professor Efetivo e Pesquisador da Universidade do Estado de Minas Gerais - UEMG. Atualmente, exerce, também, a função de Subchefe Departamental (DAE) da Faculdade de Educação da UEMG.E-mail: dan.chacon@yahoo.com.br 
mas importante introdução, intitulada "Primeiras Palavras". Nela se fazem presentes conceitos caros à reflexão freiriana, a saber: a consciência crítica e o manifesto medo da liberdade (Cf. p. 53), a práxis como unidade dialética entre objetividade e subjetividade (Cf. p. 57), o problema do sectarismo reacionário (Cf. p. 56 - 59), e, por fim, a radicalidade revolucionária (Cf. p. 59). Com efeito, estas noções ressoam em outros ensejos no decorrer da obra.

Isto posto, no primeiro capítulo, Freire expõe a contradição opressoroprimido. Nesse sentido, a opressão, enquanto um ato desumanizante, proibitivo do ser-mais do ser humano, é compreendida enquanto uma distorção da vocação histórica humana. Muito embora a desumanização seja um processo histórico, ela não se caracteriza como um destino manifesto. A opressão diz respeito, assim, a uma ordenação injusta, a uma violência que conduz, inclusive, os próprios opressores a um status de desumanizados (Cf. p. $62-63)$.

Nesse cenário, em que consiste, então, o quefazer histórico e humanista do oprimido? Conforme Freire, é tarefa inalienável destinada ao oprimido o ato de libertar-se a si mesmo e aos opressores (Cf. p. 63). Contudo, esse ato de libertação deve ser interpretado à luz de uma importante tese freiriana, qual seja: "[...] os homens se libertam em comunhão" (FREIRE, 2016, p. 95).

Com efeito, a pedagogia libertadora e humanista proposta na obra consiste de dois momentos distintos:

$$
\begin{aligned}
& \text { O primeiro, em que os oprimidos vão desvelando o mundo da } \\
& \text { opressão e vão comprometendo-se, na práxis, com a sua } \\
& \text { transformação; o segundo, em que, transformada a realidade } \\
& \text { opressora, esta pedagogia deixa de ser do oprimido e passa a } \\
& \text { ser a pedagogia dos homens em processo permanente da } \\
& \text { libertação. (FREIRE, 2016, p.74). }
\end{aligned}
$$

Os oprimidos, entretanto, hospedam em si a figura do opressor, constituindo-se, paradoxalmente, como seres duplos. O comportamento do oprimido se configura, dessa maneira, num viés prescritivo, numa introjeção da consciência do opressor, num desejo de tornar-se semelhante àquele que o oprime, vivenciando, assim, um estado de alienação e fatalismo. Há, 
portanto, entre os oprimidos, um medo da liberdade, um medo de assumi-la, enquanto que, entre os opressores, reside um medo de perdê-la, de não serem mais livres para oprimir (Cf. p. 65 - 70). Com efeito, de acordo com Freire: "a libertação é, por isto, um parto. E um parto doloroso" (FREIRE, 2016, p.70), porém, inevitável, pois, na luta pela redenção, os oprimidos deverão se valer apenas de si mesmos como modelo de sua libertação (Cf. p. 78).

Assim a libertação não é resultado do dirigismo, da propaganda ou de qualquer forma de manipulação, mas da irrupção da consciência crítica da realidade. Para uma pedagogia da libertação se faz imprescindível a crença no oprimido, ou seja, a crença de que este é capaz de libertar a si mesmo a partir da práxis. Caso se negue essa fé no humano, em sua capacidade de refletir criticamente, encerra-se, pois, a própria possibilidade do diálogo (Cf. p. 89). Nesse sentido, Freire postula, então, que: "a ação política junto aos oprimidos tem de ser, no fundo, "ação cultural", para a liberdade, por isto mesmo, ação com eles" (FREIRE, 2016, p.97).

No segundo capítulo, o autor problematiza a educação antidialógica e mecanicista que, na obra, assume a alcunha de educação bancária. Com veemência, Freire investe contra o pressuposto da educação enquanto descrição da realidade num viés estritamente estático e alheio à situação existencial dos educandos. Ora, a educação bancária, em sua única margem de ação, a de memorização de conteúdos desconectados da realidade, é, em si mesma, um instrumento da ideologia da opressão:

Na medida em que esta visão "bancária" anula o poder criador dos educandos ou o minimiza, estimulando sua ingenuidade e não sua criticidade, satisfaz aos interesses dos opressores: para estes, o fundamental não é o desnudamento do mundo, a sua transformação. $\mathrm{O}$ seu "humanitarismo", e não humanismo, está em preservar a situação de que são beneficiários [...]. (FREIRE, 2016, p.107-108).

A visão bancária se funda numa concepção fictícia do humano como ser de mera acomodação e ajustamento, destinado a ser expectador e não recriador do mundo. Com efeito, o conhecimento seria uma doação, um 
depósito da pretensa sabedoria docente sobre o educando, numa atitude, então, antidialógica, de imposição de uma cultura do silêncio, da alienação e da absolutização da ignorância discente (Cf. p. 105-106).

Conquanto, Freire contrapõe a educação bancária a partir de uma pedagogia problematizadora, libertadora e, necessariamente, dialógica:

\footnotetext{
Desta maneira, o educador já não é o que apenas educa, mas o que, enquanto educa, é educado, em diálogo com o educando que, ao ser educado, também educa. Ambos, assim, se tornam sujeitos do processo em que crescem juntos e em que os "argumentos de autoridade" já não valem. (FREIRE, 2016, p.120).

Quanto mais se problematizam os educandos, como seres no mundo e com o mundo, tanto mais se sentirão desafiados. Tão mais desafiados, quanto mais obrigados a responder ao desafio (FREIRE, 2016, p.122).
}

À vista disso, o diálogo se torna indispensável à inteligibilidade dos sujeitos cognoscentes. Nesse cenário, a máxima "ninguém educa ninguém, ninguém educa a si mesmo, os homens se educam entre si, mediatizados pelo mundo" (FREIRE, 2016, p.97) encontra seu sentido e realização. A realidade é, portanto, mediação do ato cognoscente e locus da incidência da práxis que visa à humanização.

$\mathrm{Na}$ presente obra, o humano é compreendido enquanto ser histórico, inconcluso, consciente de sua inconclusão e radicalmente aberto à busca inquieta e ao movimento de ser-mais (Cf. p. 126). Por conseguinte, uma pedagogia que reduz a educação a um status de memorização do conteúdo narrado, que cerceia a criatividade humana e que desvincula a realidade existencial dos temas discutidos é considerada por Freire como necrófila (Cf. p. 115).

A educação reflete a estrutura do poder vigente. Conquanto a estrutura opressora não permita ser interpelada pelos "porquês", de outro modo, dificulte a possibilidade do diálogo, se faz, ainda assim, oportuno uma atitude dialógica que verse, inclusive, sobre a própria negação do diálogo (Cf. p. 110).

No terceiro capítulo, a inteligência freiriana aprofunda a questão da dialogicidade enquanto essência da educação como prática da liberdade. No âmago do diálogo, se encontra a palavra. Ora, conforme Paulo Freire, a 
palavra comporta uma inteiração solidária e radical entre ação e reflexão. Dessa forma, a palavra verdadeira é, inevitavelmente, práxis (Cf. p. 133).

Nesse sentido, a existência humana é profundamente marcada pela palavra:

Existir, humanamente, é pronunciar o mundo, é modificá-lo. O mundo pronunciado, por sua vez, se volta problematizado aos sujeitos pronunciantes, a exigir deles novo pronunciar. Não é no silêncio que os homens se fazem, mas na palavra, no trabalho, na ação-reflexão. (FREIRE, 2016, p.134).

A dialogicidade, a que Freire se refere, se constitui, necessariamente, no amor, na esperança, na humildade sincera e na crença no potencial humano de criação e recriação, de compromisso, de coragem e de liberdade. O diálogo, enquanto um encontro humano para o ser-mais, se dá no verdadeiro pensar, no pensar criticamente a realidade (Cf. p. 136 - 140).

$\mathrm{Na}$ educação, o diálogo deverá se fazer presente até mesmo na investigação dos conteúdos programáticos. O conteúdo proposto não deverá ser, assim, um conjunto de informes impostos, depositados, mas uma devolução sistematizada, enriquecida e problematizada dos elementos fragmentados recebidos do povo (Cf. p. 142).

Destarte, é tarefa do educador-educando:

[...] propor ao povo, através de certas contradições básicas, sua situação existencial, concreta, presente, como problema que, por sua vez, o desafia e, assim, lhe exige resposta, não só no nível intelectual, mas no nível da ação. (FREIRE, 2016, p.146).

A fonte do conteúdo programático é, por conseguinte, a própria realidade mediatizadora. A organização do conteúdo educacional ou da ação política se dá, então, a partir da situação existencial e concreta que desvela as aspirações populares (Cf. p. 146).

A investigação que se origina a partir da realidade vivencial inaugura, pois, a dialogicidade da educação como prática de liberdade. Este movimento se projeta em direção ao que o autor chama de "universo temático do povo ou o conjunto de seus temas geradores" (FREIRE, 2016, p.147). As palavras e os temas mais significativos das experiências populares são acolhidos, problematizados e, a partir daí, se desenvolve a sistematização dos conteúdos vivenciados por estas comunidades 
epistêmicas. Irrompe, portanto, um conhecimento que se faz e refaz através da conscientização que, necessariamente, diz respeito à inserção crítica na realidade.

Os temas não devem ser, pois, acolhidos como conteúdos fragmentados, desconectados e estáticos, mas em seu devir, em sua intrínseca relação dialética com seus opostos. A interação desse conjunto de temas, que se constitui, impreterivelmente, nas relações humano-mundo, é designada, então, como o universo temático de cada época (Cf. p.155). Destarte, Freire insiste que os temas são oriundos da comunidade e, portanto, devem retornar ao povo como problemas a serem decifrados, e não como narrativas impostas (Cf. p.159).

Ainda neste capítulo, Freire se detém nos meandros da antropologia filosófica. De acordo com ele: "os homens, ao contrário do animal, não somente vivem, mas existem, e sua existência é histórica" (FREIRE, 2016, p.151). O animal, incapaz de dar sentido, vive num presente esmagador, num agora que se constitui como puro habitat. O ser humano, por sua vez, faz do presente seu espaço histórico de ação transformadora (Cf. p. 154 $155)$.

O humano se distingue, assim, dos demais entes, também, em razão de sua capacidade de tomar a si mesmo e ao mundo como objetos da própria consciência. Ademais, é característico das pessoas o enfretamento com sua realidade, denominado pelo autor como "situações-limite" (Cf. p. 153). Contudo, os obstáculos e as contradições em que as pessoas se encontram historicamente mergulhados, não são, para si, uma sentença capital. Diante, pois, das situações-limite, os seres humanos são capazes de exercer uma postura decisória no mundo "[...] do qual o ser se 'separa', e, objetivando-o, o transforma com sua ação" (FREIRE, 2016, p.153).

De acordo, então, com Freire, os temas geradores se encontram em estreita relação com as situações-limite, que, após superadas através dos "atos-limite", dão espaço ao "inédito viável”, i.e., à utopia possível (Cf. p. 146-147). 
À luz do exposto até aqui, o autor postula, portanto, a libertação como tema gerador indispensável de "nossa época" (Cf. p.158), além, é claro, do conceito antropológico de cultura (Cf. p.192-193), pois:

$\mathrm{Na}$ proporção em que discutem o mundo da cultura, vão explicitando seu nível de consciência da realidade, no qual estão implicitados vários temas. Vão referindo-se a outros aspectos da realidade, que começa a ser descoberta em uma visão crescentemente crítica. Aspectos que envolvem também outros tantos temas (FREIRE, 2016, p.193).

No último capítulo, o autor versa sobre as teorias de ação antidialógica e de ação dialógica. Inicialmente, ele retoma a questão da singularidade humana. Diferente dos animais que se encontram completamente mergulhados no mundo, como seres de puro fazer, os seres humanos são seres de práxis, podem conhecer o mundo e transforma-lo por intermédio do trabalho (Cf. p. 195).

A práxis, em Paulo Freire, se faz irredutível ao esforço ativista e ao simples verbalismo. Ademais, seria um erro conceber a práxis em momentos distintos, i.e., ora ação, ora reflexão (Cf. p. 201). Imerso nesse equívoco se encontram os falsos realistas e os famigerados idealistas. Ambos dicotomizam a práxis, sendo que estes privilegiam a reflexão, enquanto aqueles, a ação (Cf. p. 204).

No criticismo freiriano, a práxis diz respeito a uma relação dialética ação/reflexão que visa à libertação. Ora, nas páginas iniciais deste capítulo, a práxis é reafirmada pelo autor à luz do diálogo como essência da revolução: "estamos convencidos de que o diálogo com as massas populares é uma exigência radical de toda revolução autêntica. Ela é revolução por isto" (FREIRE, 2016, p. 200). Povo oprimido e liderança revolucionária numa intrínseca união dialógica na práxis.

Dessarte, a teoria da ação antidialógica é pensada a partir de suas características: "a conquista", "dividir para manter a opressão", "a manipulação" e a "invasão cultural” (Cf. p. 214). A conquista é uma redução da pessoa do dominado, de sua visão de mundo à uma coisa de somenos. Ora, o que é posto aqui em questão não se restringe a uma ação de dominação econômica, mas se manifesta, também, na dimensão cultural: 
“[...] roubando ao oprimido conquistando sua palavra também, sua expressividade, sua cultura" (FREIRE, 2016, p. 215).

A divisão para manutenção da opressão é, ela mesma, um instrumento potencializador da alienação: "quanto mais se pulverize a totalidade de uma área em 'comunidades locais' [...], tanto mais intensifica a alienação. E, quanto mais alienados mais fácil dividi-los e mantê-los divididos" (FREIRE, 2016, p. 220).

Por seu turno, a manipulação é um instrumento para a manutenção do status quo, para a massificação e para a ilusão popular: "a manipulação se faz por toda a série de mitos a que nos referimos. Entre eles, mais este: o modelo que a burguesia se faz de si mesma às massas com possibilidade de sua ascensão" (FREIRE, 2016, p. 227). Conquanto, Freire também alerta que: "enquanto populista, porém, na medida em que simplesmente manipula em lugar de lutar pela verdadeira organização popular, este tipo de líder em pouco ou quase nada serve a revolução" (FREIRE, 2016, p. 231).

A invasão cultural, por fim, presta serviço à dominação. Nesse sentido, ela possui uma natureza díade: é ela mesma dominação e, simultaneamente, é tática de dominação (Cf. p. 235). Através dela se instaura uma posse do invadido, justificando, ao mesmo tempo, a dominação em razão da suposta superioridade intrínseca ao invasor: “desrespeitando as potencialidades do ser a que condiciona, a invasão cultural é a penetração que fazem os invasores no contexto cultural dos invadidos, impondo a estes sua visão do mundo, enquanto lhes freiam a criatividade, ao inibirem sua expansão" (FREIRE, 2016, p. 234).

A reflexão freiriana se encerra, então, contrapondo as características da ação antidialógica com as da ação dialógica. São elas: a "co-laboração", a "união", a "organização" e a "síntese cultural" (Cf. p. 257). Enquanto na dominação existe uma relação de coisificação do dominado, na co-laboração há um movimento de cooperação em que os sujeitos se encontram para a transformação da realidade (Cf. p. 257). A liderança revolucionária, portanto, deverá estar em relação de íntima comunhão com o povo (Cf. p. 259). Nesse cenário, se encontra, também, a união para libertação. Na 
superação da divisão, institui-se a possibilidade de conscientização crítica das massas, de reconhecimento de si como classe oprimida (Cf. p. 259). A organização é uma dimensão pedagógica em que liderança e povo desenvolvem juntos o aprendizado e a ação. Nas palavras de Freire: "se, para a elite dominadora, a organização é a de si mesma, para a liderança revolucionária, a organização é a dela com as massas populares" (FREIRE, 2016, p. 273). Finalmente, na síntese cultural, se instaura a superação da cultura opressora e alienante. Aqui, se chega a termo o problema das diferenças de visão de mundo das lideranças e das massas. Não num esforço de negação das diferenças, mas de rejeição da imposição de uma à outra (Cf. p. 259). Conforme Freire, a superação da imposição cultural sobre os oprimidos é uma exigência axiomática para a libertação: "neste sentido é que toda revolução, se autêntica, tem de ser também revolução cultural" (FREIRE, 2016, p. 276).

Em conclusão, ainda que se considere certa dose de prolixidade na obra, seguramente, Pedagogia do oprimido se constitui como espólio da inteligência nacional. Com excelência, Freire aponta o caráter eminentemente pedagógico da luta social revolucionária, assentando suas bases na conscientização popular, exercida nos limites da práxis dialógica. Outra conquista da reflexão freiriana, digna de nota, se dá na problematização de se desassociar radicalmente vida e política, saber e prática, aquisição de instrumentos conceituais, espirituais e simbólicos daqueles que historicamente mundanizam o processo de luta e emancipação do oprimido.

Paulo Freire desenvolve, portanto, uma teoria da ação na conquista por liberdade e condições de vida digna. Nela, o oprimido torna-se protagonista de sua própria libertação a partir da consciência crítica, compreendida não como pura abstração, mas como práxis. Vida e teoria, intelectualidade e sensibilidade, revolta e amor, termos unidos numa relação dialética que visa ao comprometimento com a transformação da realidade, de sua ainda atual configuração injusta, violenta e desumanizadora. 
A originalidade da obra claramente se manifesta, também, no modo como Freire interpretou a especificidade do contexto político-pedagógico de sua época sem perder, contudo, o horizonte de diálogo com importantes pensadores da humanidade, como Karl Marx, György Lukács, Erich Fromm, Jean Paul Sartre, Reinhold Niebuhr, Simone de Beauvoir, dentre outros.

Mesmo após cinquienta anos da escrita desta obra, as provocações nela expressas permanecem explicitamente atuais. Nesse sentido, Pedagogia do oprimido é um hodierno tratado que versa sobre educação, epistemologia, ética, antropologia filosófica e política, indicado àqueles que se colocam a pergunta pela justiça, amor e misericórdia face à injustiça, dominação e desumanização. E, de modo particular, àqueles que são educadoreseducandos.

Submetido em: 11/03/2018

Aceito em: 03/04/2018

Publicado em: 04/04/2018 